\title{
The distribution of brachial plexus lesions after experimental traction: a cadaveric study
}

\author{
Krzysztof Zapałowicz, MD, and Maciej Radek, MD, PhD \\ Department of Neurosurgery, Spine and Peripheral Nerve Surgery, Medical University of Łódź, University Hospital WAM-CSW, \\ Łódź, Poland
}

\begin{abstract}
OBJECTIVE The objective of the present study was to determine experimentally the distribution of lesions caused in the cadaveric brachial plexus (BP) by excessive stretching. The authors attempted to delineate the correlation between the direction of stretching and sites of lesions.
\end{abstract}

METHODS Fifteen specimens (each comprised the spinal segment C4-T2 with 2 BPs) were harvested from adult cadavers. Each BP was stretched in a mechanical testing machine at a constant speed of $200 \mathrm{~mm} / \mathrm{min}$. Specimens were divided into 3 groups: in group A the BPs were stretched caudally at a $45^{\circ}$ angle to the spinal midline; in group B they were stretched perpendicularly to the spinal midline; and in group $C$ the stretching was caudally parallel to the midline. Lesions of each BP were identified and analyzed. A graph of load against dislocation was registered when stretching to delineate the maximal force $\left(\mathrm{F}_{\text {max }}\right)$, defined as the maximum load at which BP failure occurs.

RESULTS Based on macroscopic examination, 140 sites of mechanical damage were identified in 30 BPs. Preganglionic injuries (63.6\% of lesions), defined as avulsions of the spinal ganglia with their rootlets, were found in 89 spinal nerves. In group B-in which specimens were stretched perpendicularly to the spinal segment-preganglionic injuries were significantly more frequent (41 avulsed spinal nerves) than in groups A and C (21 and 27 avulsed spinal nerves, respectively). Postganglionic lesions equivalent to neurotmesis were found in 51 sites ( $36.4 \%$ of all lesions) along spinal nerves, trunks, divisions, and cords. Postganglionic lesions in group B were much less frequent (8) as compared with groups $A$ and $C$ (24 and 19, respectively).

CONCLUSIONS Predominance of preganglionic lesions suggests that attachments of the BP to the spine are more susceptible to traction than postganglionic elements. Preganglionic lesions were mainly produced in $\mathrm{C} 7, \mathrm{C} 8$, and $\mathrm{T} 1$ spinal nerves, suggesting their weaker attachment to the spine than in the case of C5 and C6 nerves. Preganglionic lesions were highly correlated with a traction perpendicular to the spine, whereas postganglionic lesions were provoked mainly by traction directed at $45^{\circ}$ caudally or by means of caudal traction parallel to the midline. This discrepancy implies a relationship between mechanical resistance of pre- and postganglionic elements of the BP and the vector of force.

https://thejns.org/doi/abs/10.3171/2018.5.SPINE171148

KEYWORDS biomechanics; brachial plexus; neurotmesis; spinal nerve root avulsion; traction injury

$\mathrm{T}$ HE brachial plexus (BP) is formed by the anterior rami of the spinal nerves $\mathrm{C} 5-\mathrm{T} 1$ (commonly named plexus roots). The roots anastomose to form trunks, divisions, cords, and branches-nerves. The BP begins in the neck, where it is firmly attached to the vertebrae, and ends in the upper extremity. ${ }^{12,18-20}$ Both of these structures are mobile and in certain conditions may subject the BP to destructive traction forces. ${ }^{9,16,19,20,25}$ Excessive traction is the leading cause of closed BP injuries, which most frequently result from road accidents. The incidence of closed BP injuries among motorcycle riders is significantly high. $1,4,6,11,13,16,17,23$ Also, traction is a typical cause of birthrelated BP injuries. ${ }^{10}$

The location of an injury within the plexus is important for predicting outcomes and the feasibility of surgical treatment. A preganglionic BP injury (avulsion of the rootlets from the spinal cord) is considered irreparable, whereas a postganglionic injury, which is distal to the dorsal root ganglion (DRG), may recover spontaneously or may be treated surgically. Clinical observations indicate the cor-

ABBREVIATIONS BP = brachial plexus; $D R G=$ dorsal root ganglion; $F_{\max }=$ maximal force; IVF = intervertebral foramen . SUBMITTED October 18, 2017. ACCEPTED May 11, 2018.

INCLUDE WHEN CITING Published online September 28, 2018; DOI: 10.3171/2018.5.SPINE171148. 
relation between direction of force and the area in which the plexus is damaged. 1,3,4,14,17,20,23,25,31 However, the mechanism of traction injury to the human BP has rarely been studied experimentally. 5,9,25-27,30 The present study is aimed to assess lesions produced in the dissected human BP by excessive traction at a constant speed. Traction was applied in 3 different directions to correlate the vector of load with the distribution of lesions. The local bioethics committee accepted the research program, and financial support was received from the State Committee for Scientific Research.

\section{Methods}

\section{Specimen Preparation}

Fifteen specimens were obtained from nonembalmed male cadavers (age 19-55 years; mean age 38 years) during routine autopsy procedures performed within 1-8 days after death (mean 5 days). Clinical histories were reviewed to exclude diseases affecting the neural tissue as well as any neck or shoulder trauma. Each specimen comprised spinal segment C4-T2 harvested en bloc with dural sac, spinal cord, and 2 BPs. The plexuses were isolated from the surrounding tissues as far distal as the axillary fossa, where the nerves arising from cords were cut. A stainless steel bar curved to mimic the cervical lordosis was screwed to the anterior surfaces of vertebrae. This bar served as an attachment point of the specimen to the testing machine. The specimen was irrigated with a $0.9 \%$ saline solution and stored at $5^{\circ} \mathrm{C}$. The following day, the plexuses were thawed in saline at $20^{\circ} \mathrm{C}$ and tested in the air-conditioned room at $20^{\circ} \mathrm{C} \pm 2{ }^{\circ} \mathrm{C}$, with air humidity $65 \% \pm 2 \%$.

\section{Mechanical Testing}

Specimens were mechanically tested in an INSTRON 4000 tensile testing machine. The bar screwed to the spinal segment was fastened to the steel frame, which in turn was attached to the upper, fixed crosshead of a machine connected with the load cell. The uppermost plexus was protected in a saline-soaked gauze, whereas the downward plexus was allowed to hang freely for a few minutes. Afterward, its terminal nerves were grasped in the lower grip of the machine, which was connected with the driven crosshead (Fig. 1). Specimens were divided into 3 equal groups that differed in the direction of applied load. In group A, the angle between load and spinal sagittal plane was set at $45^{\circ}$ caudally. In group B, the load was perpendicular to the spinal sagittal plane. Last, in group $C$, the load was directed caudally parallel to the spinal segment. The load vector in group A simulated the traction of the plexus toward axilla, in group B it simulated lateral traction of the arm, and in group $\mathrm{C}$ it simulated downward traction of the arm (Fig. 2). Traction was applied to the plexus at a crosshead speed of $200 \mathrm{~mm} / \mathrm{min}$ in a frontal plane passing through the C7 intervertebral foramen (IVF). Plexus was stretched to failure, which manifested itself as a rapid decrease of resistance after the ultimate load. In the next step, the bar holding the spinal segment was mounted in the machine in an inverted position and the contralateral plexus was tested using the same experimental protocol. A graph of load against dislocation was registered when stretching to delineate the maximal force $\left(\mathrm{F}_{\max }\right)$, defined as the maximum load at which BP failure occurs. The values of force obtained in the 3 experimental groups were analyzed to verify whether in fact the mechanical resistance of the BP does correlate with the direction of traction.

\section{Statistical Analysis}

For the purpose of statistical analysis, the KruskalWallis and the Mann-Whitney U-tests were used (STATISTICA Software; StatSoft), and p $<0.05$ was considered significant. A post hoc Bonferroni correction was also calculated to rule out any errors that might show false statistical significance.
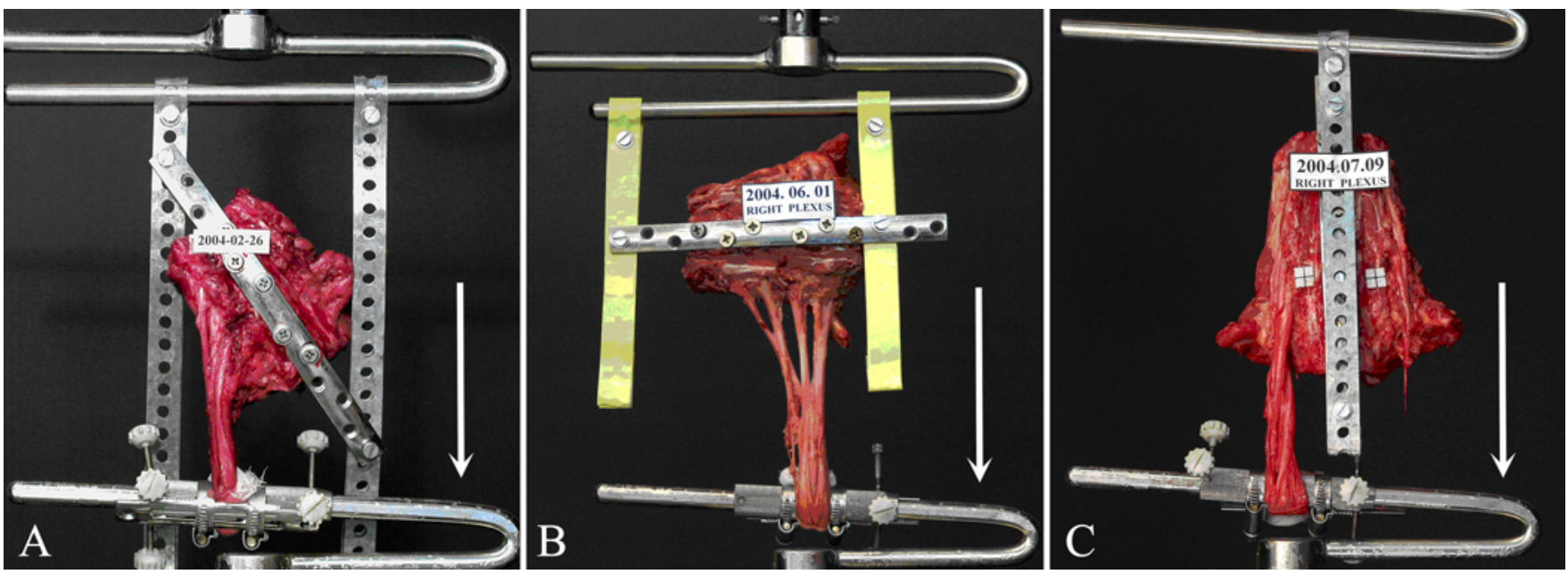

FIG. 1. Photographs demonstrating cadaveric BP specimens gripped in the tensile testing machine. The spine is attached to the upper crosshead by means of a steel bar screwed to the vertebrae. The terminal nerves of the plexus are clamped to the lower, driven crosshead. Arrows indicate the vector of force. A: Oblique position of the spinal segment; the angle between the BP and the spine was set at approximately $45^{\circ}$. B: The spinal segment in horizontal position, stretching perpendicularly to the spine. C: The spinal segment attached vertically, stretching caudally, force parallel to the spine. 

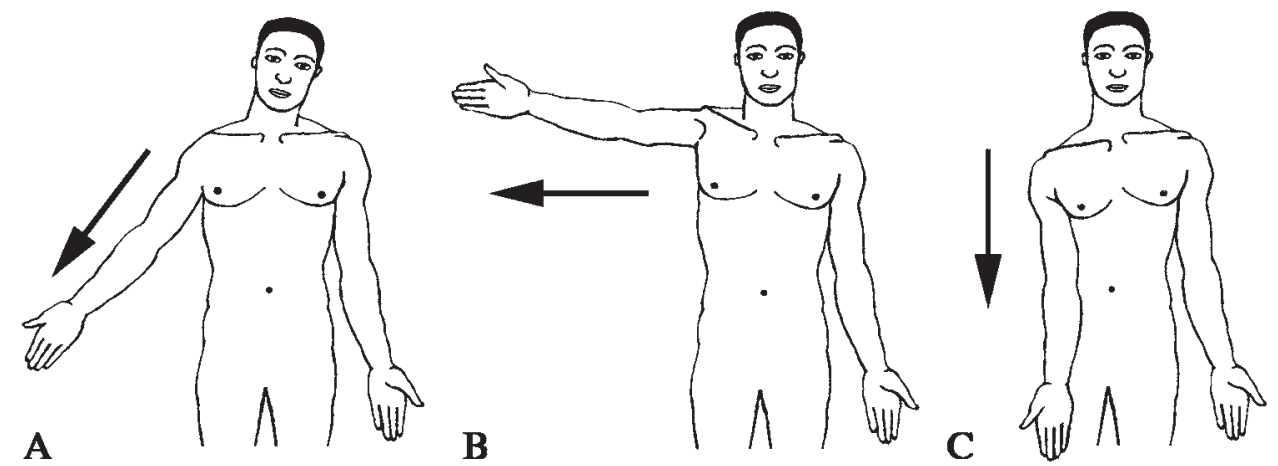

FIG. 2. Drawings showing possible mechanisms of closed BP injuries simulated during the experiment. Arrows indicate the vector of force. A: The abducted arm pulled downward, with contralateral neck flexion. B: Lateral traction of the abducted arm. C: Depression of the shoulder by a heavy impact on or forcible caudal traction of the arm. Copyright Krzysztof Zapałowicz. Published with permission.

\section{Anatomical Study}

After failure of both plexuses, an autopsy of the specimen was performed to identify sites of experimentally produced lesions and to estimate their distribution.

\section{Results}

Traction produced 140 injuries in 30 plexuses: 89 (63.6\%) preganglionic and 51 (36.4\%) postganglionic (Tables 1 and 2). Typical preganglionic injury, which was seen in 81 spinal nerves, comprised avulsion of the spinal nerve with its DRG and with the rootlets from the IVF (Fig. 3). In 74 nerves the rootlets were wholly avulsed from the spinal cord, and in 7 nerves a certain number of rootlets was ruptured between the DRG and the spinal cord (Fig. 3 left). Atypical avulsions (skip lesions) were found in 8 spinal nerves: in group A, one C5; in group B, two C5; and in group $\mathrm{C}$, two $\mathrm{C} 5$, two $\mathrm{C} 6$, and one $\mathrm{C} 7$. In these cases epineurium was disrupted distally to adjacent transverse processes and $20-55 \mathrm{~mm}$ outside the DRG, whereas perineurium with the corresponding DRG and rootlets was avulsed (Figs. 3 [right] and 4). Preganglionic lesions were most frequent in group B-41 nerves were avulsed, mainly $\mathrm{C} 6$ and $\mathrm{C} 7$. In groups $\mathrm{A}$ and $\mathrm{C}$ the number of preganglionic lesions was similar (21 and 27, respectively); they dominated in caudal nerves C8 and T1. The majority of preganglionic avulsions were produced in the spinal nerves $\mathrm{C} 7, \mathrm{C} 8$, and $\mathrm{T} 1-$ each having 20 lesions.

The postganglionic lesions were defined as loss of

TABLE 1. The distribution of preganglionic lesions (avulsions)

\begin{tabular}{ccccc}
\hline & \multicolumn{4}{c}{ No. of Lesions } \\
\cline { 2 - 5 } Spinal Nerve & Group A & Group B & Group C & Total \\
\hline C5 & 3 & 8 & 2 & 13 \\
\hline C6 & 3 & 10 & 3 & 16 \\
\hline C7 & 4 & 10 & 6 & 20 \\
\hline C8 & 6 & 6 & 8 & 20 \\
\hline T1 & 5 & 7 & 8 & 20 \\
\hline Total & $21(24 \%)$ & $41(46 \%)$ & $27(30 \%)$ & 89 \\
\hline
\end{tabular}

continuity of a nerve trunk, with a gap between stumps (disruptions equivalent to neurotmesis). These lesions significantly dominated in divisions and cords of plexuses belonging to groups $\mathrm{A}$ and $\mathrm{C}$ (Table 2). The detailed distribution of all lesions is summarized in Fig. 5. The values of ultimate load at mechanical failure are listed in Table 3. There was no evidence of correlation between the directions of traction and values of ultimate load $(p>0.05)$. The Kruskal-Wallis test did not find any significant difference in force values between groups $\mathrm{A}, \mathrm{B}$, and $\mathrm{C}(\mathrm{H}$-statistics $=2.499 ; \mathrm{p}=0.286$ ). Also, the Mann-Whitney U-test supported the finding of no significant difference in force values in relation to the following pairs of groups: A versus $B(p=0.143)$, A versus $C(p=0.578)$, and $B$ versus $C(p$ $=0.333$ ). Statistical analysis led to the conclusion that the direction of force had no influence on the mechanical resistance of BP to traction.

\section{Discussion}

The BP begins in the neck, where it is firmly attached to the C4-T1 spinal segment, and ends in the axilla. ${ }^{12,18-20}$ It can be damaged by excessive tension when the head and neck are forced away from the shoulder, which happens during a violent motion or traction to the upper limb. ${ }^{1,4,16,19,25}$ Anatomically, the BP lesions can be divided into 2 categories: preganglionic and postganglionic. The former comprise avulsion of a spinal nerve with DRG and rootlets from their anatomical sites, whereas the latter are

TABLE 2. The distribution of postganglionic lesions (neurotmesis)

\begin{tabular}{lcccc}
\hline & \multicolumn{4}{c}{ No. of Lesions } \\
\cline { 2 - 5 } Site of Rupture & Group A & Group B & Group C & Total \\
\hline Anterior rami & 4 & 3 & 3 & 10 \\
\hline Trunks & 1 & 1 & 1 & 3 \\
\hline Divisions & 10 & 2 & 7 & 19 \\
\hline Cords & 9 & 2 & 8 & 19 \\
\hline Total & $24(47 \%)$ & $8(16 \%)$ & $19(37 \%)$ & 51 \\
\hline
\end{tabular}



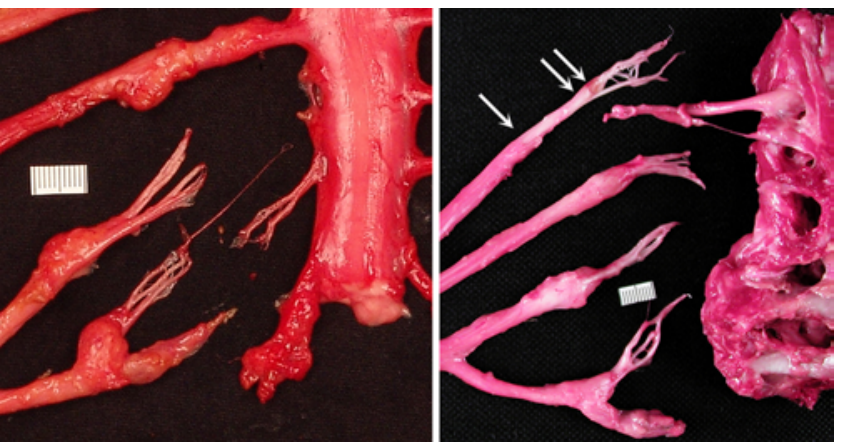

FIG. 3. Preganglionic injuries. Left: Group C, specimen 2, right plexus. All $\mathrm{C} 7$ rootlets are avulsed from the spinal cord, and the portion of $\mathrm{C} 8$ rootlets is ruptured between the spinal cord and the DRG. Right: Group $B$, specimen 1, right plexus. The epineurium of anterior branch $\mathrm{C} 5$ is disrupted (arrow) outside the ganglion, and the perineurium, spinal ganglion (double arrow), and rootlets were avulsed through the epineurial tube.

the same as neurapraxia, axonotmesis, or neurotmesis. ${ }^{16,17,20}$ The nerve fibers passing through the spinal nerves are protected against traction by epineurium and perineurium composed of collagen, in contrast to the rootlets, which pass within the dural sac and lack connective tissue. 2,12,20,26 Force is transmitted along the BP to the spinal ganglia and finally to the weak rootlets. Both of these structures are protected against pulling out (avulsion) by fibrous attachments binding the spinal nerves to the transverse processes and the ganglia to the IVFs. $2,4,5,8,9,12,15,18-21,26,27$

The IVF in the subaxial cervical spine is limited by the following: 1) the inferior part of the superjacent vertebral body, the uncovertebral joint, and the posterolateral part of the anulus fibrosus anteriorly; 2) adjacent pedicles inferiorly and superiorly; and 3) the medial aspect of the facet joint posteriorly. Outside the foramina arise the transverse processes directed laterally and forward; each consists of an anterior and a posterior part. The anterior part arises from the side of the vertebral body and ends in the anterior tubercle (which is absent in the C7 vertebra). The posterior part arises from the vertebral arch behind the foramen and ends in the posterior tubercle. In the transverse processes of C5 and C6, a bar of bone that exhibits a groove on its upper surface joins these 2 parts. However, in the C7 transverse process the anterior tubercle is absent and the groove is flat. Outside the IVF the spinal nerves C5-7 and their ganglia lie in this groove posteriorly to the vertebral artery.,12,18,22,26,29 The spinal nerves C8 and T1 lack underlying transverse processes; they leave the spinal canal in the proximity of the first rib. 7,12,18,22,29 Outside the IVF, the $\mathrm{BP}$ passes through the scalene triangle-space between the scalene muscles with the first rib at the base. ${ }^{18,31}$

The attachments of the BP roots to the spine have been investigated in order to elucidate the mechanism of traction injuries..$^{9,15,21,26,27,31}$ In 1951 Frykholm observed that the epineurium of the cervical spinal nerve and ganglion is firmly anchored in the groove of the underlying transverse process. Moreover, the ligaments descending from the transverse processes of C4-6 reinforce the epineurial sheaths of the trunks lying below. ${ }^{8,9}$ In studies that Sunderland published in 1974, he did not find any attachments binding the radicular nerves to the IVF. He stated that the spinal nerves are attached to the transverse processes. Of all the spinal nerves forming the BP, the C5 and C6 nerves have the strongest attachment to the transverse processes by means of the following: 1) fixation of the epineurial sheath in the relatively deep groove of the underlying

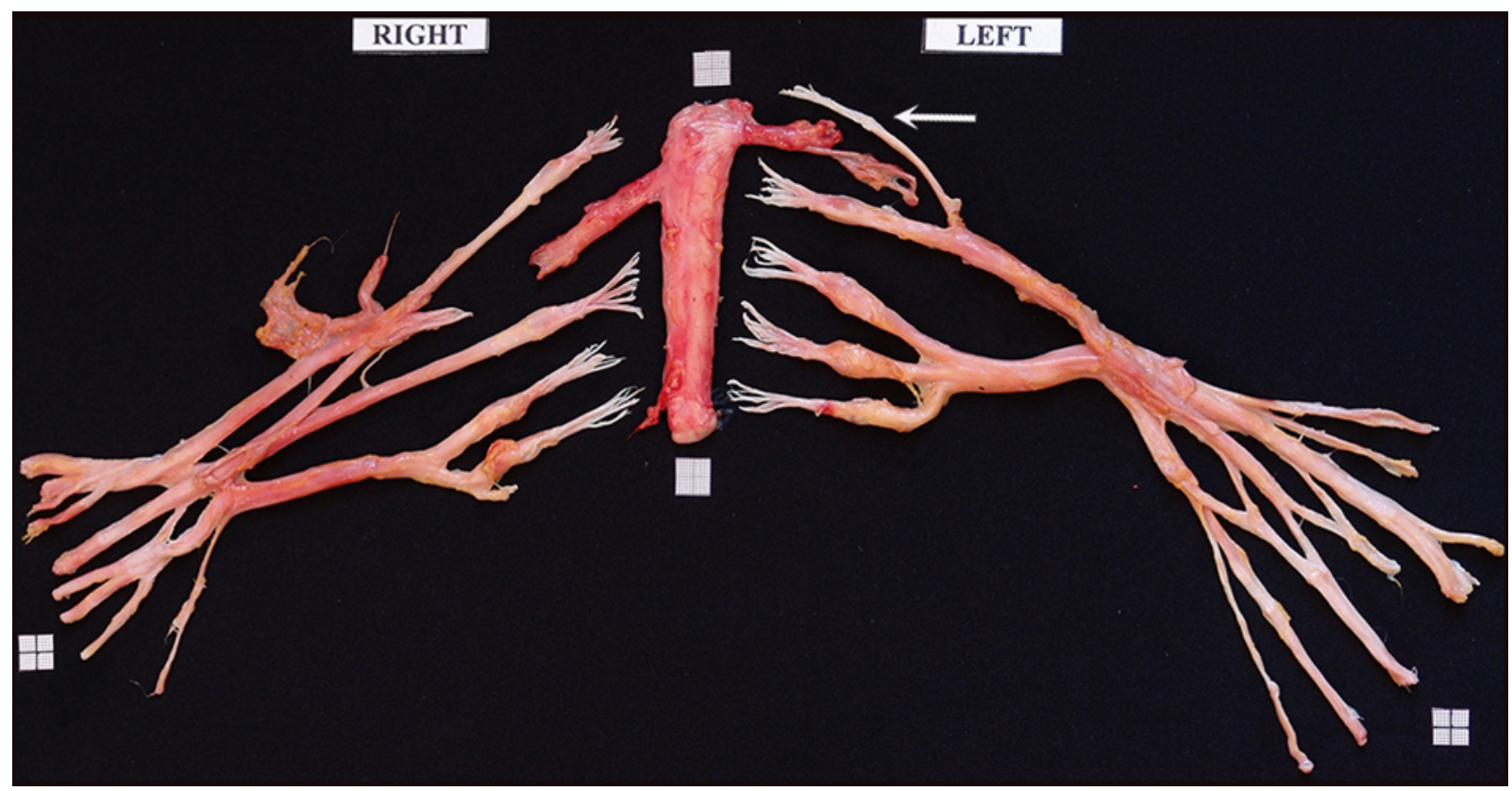

FIG. 4. Specimen 5, group C, anterior view (photograph). The right plexus shows avulsions of the spinal nerves C5 and C7-T1, and rupture of the anterior branch of $\mathrm{C} 6$ with a gap between the stumps. The left plexus shows avulsions of the spinal nerves $\mathrm{C5}-$ T1, and epineurium at the C5 level was disrupted (arrow) outside the DRG and externally on adjacent transverse process. 


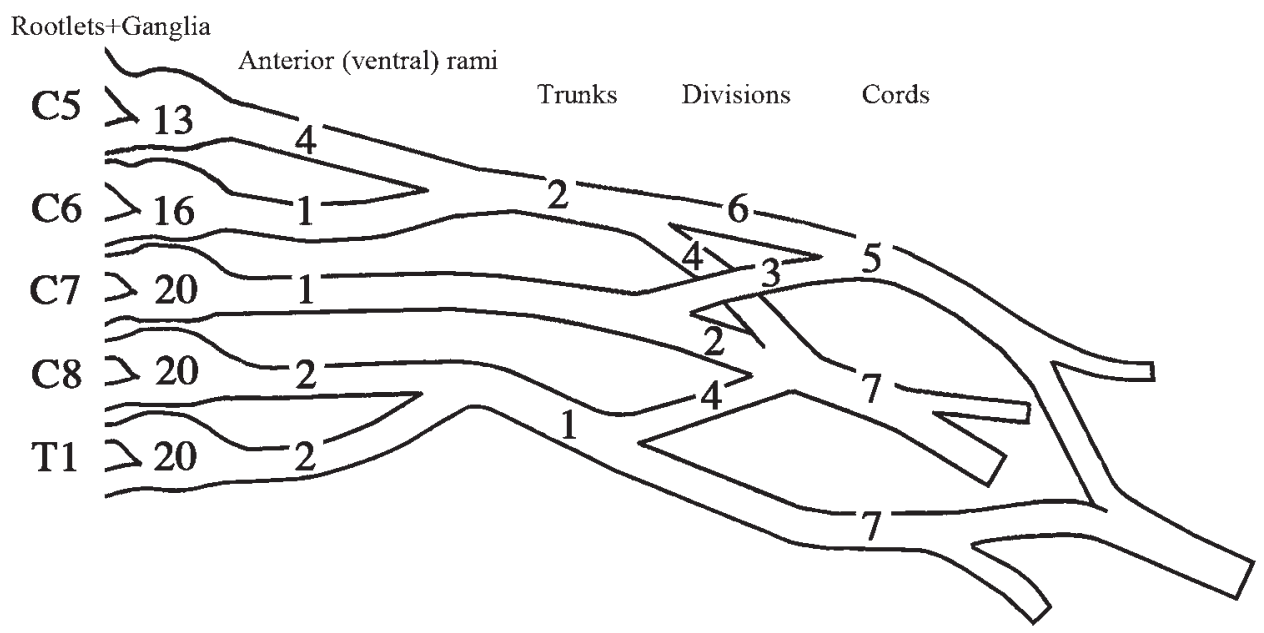

FIG. 5. A graphic presentation of the number and location of lesions produced in $30 \mathrm{BPs}$.

transverse process; 2) attachments to the prevertebral fascia; 3) slips from the muscles and tendons attached to the transverse processes; and 4) fibrous slips descending from the transverse process above to join the epineurium of the spinal nerve below. ${ }^{26,27}$

According to a study published by Kraan et al. ${ }^{15}$ in 2011 , the extraforaminal ligaments in the C2-T1 spinal segment form 2 main parts: the ventral and the dorsal ligaments. Each ventral and dorsal ligament in turn consists of a superior and an inferior part. The ventral superior ligament originates from the uncovertebral joint and the cranial transverse process, and inserts on the ventral part of the spinal nerve. The ventral inferior ligament originates from the anterior and posterior tubercle of the caudal transverse process and inserts on the caudal part of the spinal nerve. The dorsal superior ligament originates from the cranial transverse process, passes the nerve on its dorsal side, and inserts on the caudal transverse process. The dorsal inferior ligament stems from the anterior and posterior tubercle of the caudal transverse process and inserts on the caudal part of the spinal nerve. The superior ligaments are positioned perpendicularly to the nerve, whereas the inferior ligaments are parallel. The spinal nerves $\mathrm{C} 8$ and $\mathrm{T} 1$ have all-around attachment to the transverse process of the $\mathrm{C} 7$ vertebra and to the T1 vertebra. ${ }^{15}$

In 2015 Shi et al. described the radiating ligaments situated outside the IVF in the C2-T1 spinal segment. ${ }^{21}$ These ligaments are further grouped into 4 categories: 1) superior, originating from the cranial transverse process and joining the upper part of the nerve sheath lying below; 2) inferior (the most significant), originating from the anterior and posterior tubercle of the transverse process, they pass parallel to the nerve and connect the cranial nerve to the groove of the transverse process; 3) anterior, originating from the capsule of the uncovertebral joint; and finally, 4) posterior radiating ligaments branching off of the capsule of the facet joint. All groups of the radiating ligaments fuse with the periradicular sheath of the cervical spinal nerve. Their mechanical role is to act against the lateral traction of the nerve. ${ }^{21}$ To summarize, the ligaments binding the cervical spinal nerve to the transverse process serve as protection against pulling forces.9, ${ }^{9,15,21,26,27}$ The nerves C5-7 are attached to the corresponding transverse process, and thus have stronger attachments to the spine than C8 and T1. This anatomical difference explains the most common preganglionic lesions of nerves $\mathrm{C} 8$ and T1. ${ }^{4,5,10,12,14,17,27,31}$

Based on the clinical observations of different authors, the relationship between direction of traction and distribution of the BP lesions may be summarized as follows: 1) downward movement of the arm/shoulder with contralateral neck flexion damages upper plexus (C5-7 nerves or upper trunk), ${ }^{1,3,4,17,20,23,31}$ 2) dorsal traction of abducted arm combined with contralateral neck rotation damages the trunks; ${ }^{1,4} 3$ ) upward traction of abducted arm damages nerves C7-T1 or middle and inferior trunk:1,3,17,20,23,31 4) anteroposterior movement of the shoulder damages $\mathrm{C} 7 \mathrm{spi-}$ nal nerve; ${ }^{3,31}$ or 5) abduction of the arm combined with interior rotation stretches the infraclavicular part of the $\mathrm{BP}^{4}$

TABLE 3. The maximum load at BP failure for each group

\begin{tabular}{|c|c|c|c|c|}
\hline \multirow[b]{2}{*}{ Specimen } & \multirow[b]{2}{*}{ Plexus } & \multicolumn{3}{|c|}{$\mathrm{F}_{\max }(\mathrm{N})$} \\
\hline & & Group A & Group B & Group C \\
\hline \multirow[t]{2}{*}{1} & Rt & 715.0 & 712.0 & 584.0 \\
\hline & $\mathrm{Lt}$ & 720.0 & 719.0 & 757.0 \\
\hline \multirow[t]{2}{*}{2} & Rt & 804.0 & 441.0 & 686.0 \\
\hline & $\mathrm{Lt}$ & 735.0 & 365.0 & 701.0 \\
\hline \multirow[t]{2}{*}{3} & Rt & 689.0 & 559.0 & 644.0 \\
\hline & $\mathrm{Lt}$ & 566.0 & 557.0 & 719.0 \\
\hline \multirow[t]{2}{*}{4} & Rt & 564.0 & 621.0 & 585.0 \\
\hline & $\mathrm{Lt}$ & 571.0 & 576.0 & 468.0 \\
\hline \multirow[t]{2}{*}{5} & Rt & 687.0 & 694.0 & 603.0 \\
\hline & $\mathrm{Lt}$ & 604.0 & 637.0 & 577.0 \\
\hline \multicolumn{2}{|c|}{ Minimum-maximum } & $564.0-804.0$ & $365.0-719.0$ & $468.0-757.0$ \\
\hline \multicolumn{2}{|c|}{ Mean \pm SD } & $665.0 \pm 83.9$ & $588.0 \pm 115.7$ & $632.0 \pm 85.8$ \\
\hline \multicolumn{2}{|l|}{ Median } & 688.0 & 598.5 & 623.5 \\
\hline
\end{tabular}

$\mathrm{N}=$ newton. 
The experimental literature on $\mathrm{BP}$ biomechanics is scant. ${ }^{28}$ As described by Gilbert and Pivato, Fieux (1897) studied the mechanical factors of obstetrical BP injuries and conducted some experiments on rabbits., ${ }^{9,10,16}$ Stevens was probably the first to study different vectors of mechanical load applied to the BP in adult cadavers. . $^{16,25}$ In his 1951 study, Frykholm registered the movements of the rootlets in the spinal canal in different positions of the neck and the upper extremity. He concluded that such factors as traction of the arm or dislocation of the shoulder girdle might place an increased strain on the plexus. ${ }^{9}$ In 1986, Destandau et al. ${ }^{5}$ biomechanically tested traction of human C5-T1 spinal nerves and observed that avulsion of roots of the spinal nerve was preceded by simultaneous lesions in 2 different anatomical sites: 1) rupture of the ligaments binding the nerve in the groove of the transverse process, and 2) rupture of the dura mater. They observed $67 \%$ of postganglionic ruptures (predominantly C5, C6, and $\mathrm{C} 7$ attached to the transverse processes) and 33\% of avulsions (predominantly C8 and T1), and concluded that spinal nerves are weaker than their attachments to the transverse processes with the dura put together. ${ }^{5}$ However, one should keep in mind that mechanical properties of short spinal nerves exposed to traction may differ from properties of the BP stretched as a whole structure. Also, the specimens tested by Destandau et al. were stored frozen at a temperature of $-20^{\circ} \mathrm{C}$, which might have influenced their mechanical resistance.

In their 1989 study, Kawai et al. stretched the BP of rabbits in 3 different directions and arrived at the conclusion that the direction of traction force determined the site and the level of the BP lesion. ${ }^{14}$ In their experiments, cranial or lateral traction produced avulsions of C6-T1 nerves, whereas C5 nerves had postganglionic lesions only. Caudal traction produced only avulsion of terminal nerves of the BP from the muscles. ${ }^{14}$ In a study published in 2000 , Spinner et al. stretched the BP of rats by lateral traction of the upper limb, and obtained avulsions of all nerves, predominantly $\mathrm{C} 6$ and $\mathrm{C} 7$. The results demonstrated that all attachments of spinal nerves to the spine were weaker than postganglionic structures. ${ }^{24}$ In 2002, Takai et al. stretched the $\mathrm{BP}$ of rabbits laterally to study the nerve conduction under load. In their experiments, the compound muscle action potential disappeared with a strain of $8.1 \%$. However, stretching was discontinued to produce mechanical failure of the BP. ${ }^{28}$

In the present study, preganglionic lesions dominated over postganglionic lesions $(63.6 \%$ and $36.4 \%$, respective1y). This observation is consistent with statistics of injuries found in victims with closed traumatic injuries of the BP. ${ }^{13,17,31}$ Preganglionic avulsions were produced in 59\% of 150 spinal nerves, whereas ruptures appeared in $10 \%$ of 510 postganglionic elements (anterior rami, trunks, divisions, and cords put together). In group B, avulsions were most common (41 of 50 spinal nerves); conversely, the incidence of postganglionic lesions was minimal (8 elements). This striking disproportion leads to a conclusion that attachments of the BP to vertebrae are highly susceptible to lateral traction and that when pulled laterally they are weaker than postganglionic elements. One may hypothesize that laterally directed force first puts under tension and damages a part of the attachments passing between the anterior rami and the corresponding transverse processes; second, the remaining portion of the binding structures is torn off. Force directed $45^{\circ}$ caudally (group A) is more or less parallel to the $\mathrm{BP}$, and in consequence it may simultaneously charge (i.e., put under traction) the attachments to the spine, which acting together may withstand a greater load than postganglionic parts of the BP. In group $\mathrm{A}$, the nerves $\mathrm{C} 8$ and $\mathrm{T} 1$ were most frequently avulsed, which may be explained by the lack of corresponding transverse processes. Finally, caudal stretching (group C) produced avulsions mainly in lower nerves C8 and $\mathrm{T} 1$, probably because the anterior rami $\mathrm{C} 5-7$ were supported by the transverse processes. In groups A and $\mathrm{C}$, the nerves $\mathrm{C} 8$ and $\mathrm{T} 1$ were most frequently avulsed. This fact may be credited to the lack of attachments to the transverse processes; this observation is consistent with the data in the literature. ${ }^{4,5,14,20}$

\section{Limitations of the Study}

The present study is innovative-human BPs were stretched as whole structures dissected from the surrounding tissues. The described experimental model allowed for correlation of the distribution of lesions with the direction of force. Worth mentioning are some limitations this study is facing at the moment: the plexuses were stretched with relatively low crosshead speed, as compared with speeds encountered in automotive accidents; for technical reasons, traction with higher speeds could not be realized; and only 3 vectors of traction were studied in the experimental model. Note that microscopic examinations of lesions were not planned.

\section{Conclusions}

Our findings were as follows. 1) Predominance of preganglionic lesions suggests that attachments of the BP to the spine are more susceptible to traction than are postganglionic elements. 2) The preganglionic lesions were mainly produced in $\mathrm{C} 7, \mathrm{C} 8$, and $\mathrm{T} 1$ spinal nerves, suggesting their weaker attachment to the spine than in the case of $\mathrm{C} 5$ and C6 nerves. 3) Preganglionic lesions were highly correlated with a traction perpendicular to the spine, whereas postganglionic lesions were provoked mainly by traction directed at $45^{\circ}$ caudally or by means of caudal traction parallel to the midline. This discrepancy implies a relationship between mechanical resistance of pre- and postganglionic elements of the BP and the vector of force.

\section{Acknowledgments}

We thank Adam Dudziński, MA, for his linguistic review of the manuscript.

\section{References}

1. Barnes R: Traction injury of the brachial plexus in adults. J Bone Joint Surg 31-B:10-16, 1949

2. Bonnel F, Rabishong P: Anatomie et systématisation du plexus brachial de l'adulte. Anat Clin 2:289-298, 1980

3. Brunelli GA, Brunelli GR: A fourth type of brachial plexus lesion: the intermediate (C7) palsy. J Hand Surg Br 16:492494, 1991 
4. Coene LNJEM: Mechanisms of brachial plexus lesions. Clin Neurol Neurosurg 95 (95 Suppl):S24-S29, 1993

5. Destandau J, Micallef JP, Rabischong P: An experimental study of traction on the cervical spinal nerves. Surg Radiol Anat 8:197-204, 1986

6. Dubuisson AS, Kline DG: Brachial plexus injury: a survey of 100 consecutive cases from a single service. Neurosurgery 51:673-683, 2002

7. Ebraheim NA, An HS, Xu R, Ahmad M, Yeasting RA: The quantitative anatomy of the cervical nerve root groove and the intervertebral foramen. Spine (Phila Pa 1976) 21:16191623,1996

8. Frykholm R: Cervical epidural structures, periradicular and epineurial sheaths. Acta Chir Scand 102:10-20, 1951

9. Frykholm R: The mechanism of cervical radicular lesions resulting from friction or forceful traction. Acta Chir Scand 102:93-98, 1951

10. Gilbert A, Pivato G: Obstetrical palsy: the French contribution. Semin Plast Surg 19:5-16, 2005

11. Jain DK, Bhardwaj P, Venkataramani H, Sabapathy SR: An epidemiological study of traumatic brachial plexus injury patients treated at an Indian centre. Indian J Plast Surg 45:498-503, 2012

12. Johnson EO, Vekris MD, Zoubos AB, Soucacos PN: Neuroanatomy of the brachial plexus: the missing link in the continuity between the central and peripheral nervous systems. Microsurgery 26:218-229, 2006

13. Kaiser R, Waldauf P, Haninec P: Types and severity of operated supraclavicular brachial plexus injuries caused by traffic accidents. Acta Neurochir (Wien) 154:1293-1297, 2012

14. Kawai H, Ohta I, Masatomi T, Kawabata H, Masada K, Ono K: Stretching of the brachial plexus in rabbits. Acta Orthop Scand 60:635-638, 1989

15. Kraan GA, Smit TH, Hoogland PVJM: Extraforaminal ligaments of the cervical spinal nerves in humans. Spine $\mathbf{J}$ 11:1128-1134, 2011

16. Leffert RD: Closed injury to the brachial plexus, in Leffert LD (ed): Brachial Plexus Injuries. New York: Churchill Livingstone, 1985, pp 39-55

17. Moran SL, Steinmann SP, Shin AY: Adult brachial plexus injuries: mechanism, patterns of injury, and physical diagnosis. Hand Clin 21:13-24, 2005

18. Muset i Lara A, Dolz C, Rodríguez-Baeza A: Anatomy of the brachial plexus, in Gilbert A (ed): Brachial Plexus Injuries. London: Martin Dunitz Ltd, 2001, pp 3-15

19. Rozing PM: The topographical anatomy of the brachial plexus. Clin Neurol Neurosurg 95 Suppl:S12-S16, 1993

20. Sakellariou VI, Badilas NK, Mazis GA, Stavropoulos NA, Kotoulas HK, Kyriakopoulos S: Brachial plexus injuries in adults: evaluation and diagnostic approach. ISRN Orthop 2014:726103, 2014

21. Shi B, Zheng X, Zhang H, Sun C, Cao Y, Jin A, et al: The morphology and clinical significance of the extraforaminal ligaments at the cervical level. Spine (Phila Pa 1976) 40:E9-E17, 2015

22. Sioutas G, Kapetanakis S: Clinical anatomy and clinical significance of the cervical intervertebral foramen: a review. Folia Morphol (Warsz) 75:143-148, 2016
23. Songcharoen P: The adult traumatic brachial plexus. Etiology, in Gilbert A (ed): Brachial Plexus Injuries. London: Martin Dunitz Ltd, 2001, pp 47-50

24. Spinner RJ, Khoobehi A, Kazmi S, Krumreich JA, Zhao S, Zhang Z, et al: Model for avulsion injury in the rat brachial plexus using passive acceleration. Microsurgery 20:94-97, 2000

25. Stevens JH: Brachial plexus paralysis, in Codman EA (ed): The Shoulder. Boston: EA Codman, 1934

26. Sunderland S: Mechanisms of cervical nerve root avulsion in injuries of the neck and shoulder. J Neurosurg 41:705-714, 1974

27. Sunderland S: Meningeal-neural relations in the intervertebral foramen. J Neurosurg 40:756-763, 1974

28. Takai S, Dohno H, Watanabe Y, Yoshino N, Ogura T, Hirasawa Y: In situ strain and stress of nerve conduction blocking in the brachial plexus. J Orthop Res 20:1311-1314, 2002

29. Tanaka N, Fujimoto Y, An HS, Ikuta Y, Yasuda M: The anatomic relation among the nerve roots, intervertebral foramina, and intervertebral discs of the cervical spine. Spine (Phila Pa 1976) 25:286-291, 2000

30. Zapałowicz K, Radek A: Experimental investigations of traction injury of the brachial plexus. Model and results. Ann Acad Med Stetin 51:11-14, 2005

31. Zhong LY, Wang AP, Hong L, Chen SH, Wang XQ, Lv YC, et al: Microanatomy of the brachial plexus roots and its clinical significance. Surg Radiol Anat 39:601-610, 2017

\section{Disclosures}

Dr. Zapałowicz received financial support and royalties from the State Committee for Scientific Research in Poland (grant KBN 3P05C7222).

\section{Author Contributions}

Conception and design: Zapałowicz. Acquisition of data: Zapałowicz. Analysis and interpretation of data: Zapałowicz. Drafting the article: Zapałowicz. Critically revising the article: both authors. Reviewed submitted version of manuscript: both authors. Approved the final version of the manuscript on behalf of both authors: Zapałowicz. Statistical analysis: Zapałowicz. Administrative/technical/material support: Radek. Study supervision: Radek. Experiments and photographs: Zapałowicz.

\section{Supplemental Information}

\section{Previous Presentations}

Portions of this work were presented as proceedings at the 13th World Congress of Neurological Surgery, in Marrakesh, Morocco, June 19-24, 2005.

\section{Correspondence}

Krzysztof Zapałowicz: Medical University of Łódź, University Hospital WAM-CSW, Łódź, Poland. krzysztofzapalowicz1@ wp.pl. 